\title{
Early life stress and psychopharmacology
}

\author{
Lawrence H. Price • Thomas Steckler
}

Received: 3 February 2011 /Accepted: 3 February 2011 / Published online: 16 February 2011

(C) Springer-Verlag 2011

The concept of early life stress (ELS) has long been a central focus in clinical psychiatry and psychology, owing in no small part to the primacy of this concept in psychoanalytic theory. Perhaps in response to that legacy, both clinical and preclinical biologically oriented researchers have become increasingly invested in understanding the adult sequelae of adverse environmental factors occurring early in development.

Several factors stand out in considering the drivers of this changing zeitgeist: (1) new efforts to integrate preclinical and clinical findings on the pathogenesis of major psychiatric disorders, especially by focusing on model neurobiological systems (e.g., Heim et al. 1997); (2) empirical demonstration of the relevance of the classic diathesis-stress theory using gene $\times$ environment $(\mathrm{G} \times \mathrm{E})$ experimental designs (e.g., Caspi et al. 2003) and, more recently, epigenetic approaches (e.g., McGowan and Szyf 2010); (3) increased recognition of the adverse psychiatric and biomedical sequelae of ELS (e.g., Gluckman and Hanson 2004; Scott et al. 2010); (4) convincing demonstration of ELS as a major global public health challenge (e.g., Krug et al. 2002). The diversity of work covered in this Special Issue reflects the remarkable progress that has been made in this area in a relatively brief span of time.

L. H. Price $(\bowtie)$

Department of Psychiatry and Human Behavior, The Warren Alpert Medical School of Brown University, Butler Hospital, 345 Blackstone Blvd.,

Providence, RI 02906, USA

e-mail: lawrence_price_md@brown.edu

T. Steckler

Neuroscience Drug Discovery, Janssen Research \& Development,

Turnhoutseweg 30,

2340 Beerse, Belgium

e-mail: tsteckle@its.jnj.com
The relationship between ELS and clinical phenotypes remains a major focus of investigation. The review by Yehuda et al. (2010), published in October as a prelude to the present issue, examines how ELS interacts with adulthood stressors in the pathogenesis of post-traumatic stress disorder. The review by Enoch (2010) of the role of ELS in the development of alcohol and drug abuse underscores the pluripotentiality of early adversity. From the developmental perspective, Rudolph et al. (2010) present a study showing how individual differences in stress sensitivity shape the clinical response to peer victimization in children. This is mirrored in the preclinical arena, with findings that animals exposed to ELS are affected in their response to drugs of abuse (Rodrigues et al. 2010), cognitive function (Hedges and Woon 2010; Jones et al. 2010; Oomen et al. 2010), anxiety-related behaviors (Peleg-Raibstein and Feldon 2010), depression- and psychosis-related behaviors (Markham and Koenig 2010), stress sensitivity and hypothalamic-pituitary-adrenal (HPA) axis function (Claessens et al. 2010), and sleep (Pryce et al. 2010), as well as in the brain-gut axis (modeling aspects of irritable bowel syndrome) (O'Mahony et al. 2010). Certainly, limitations to these models do exist (Schmidt et al. 2010; Van Waes et al. 2010), reflecting a variety of individual differences (Claessens et al. 2010), including whether animals are tested during adolescence or adulthood (Peleg-Raibstein and Feldon 2010).

Long-term cognitive sequelae of ELS are now well documented, and two reviews in this issue address this burgeoning literature. Hedges and Woon (2010) organize the findings with an emphasis on specific functional effects, while Pechtel and Pizzagali (2010) utilize a neurodevelopmental framework to integrate observations on cognitive and affective processes.

The seminal preclinical studies of ELS and the HPA axis (Claessens et al. 2010; O'Malley et al. 2010), which 
mirrored clinical observations of HPA dysfunction in depression, have spurred a closer look at ELS and HPA function in humans. Ouellet-Morin et al. (2010) demonstrate that even "safe" levels of antenatal exposure to alcohol can disrupt salivary cortisol responses to stress in infants. Turner-Cobb et al. (2010) show that children with higher evening salivary cortisol levels during the stress of entering primary school experience fewer upper respiratory infections, illustrating the capacity of ELS to facilitate adaptive responses in certain contexts. Hagan et al. (2010) report that positive parenting following parental death can mitigate the effects of subsequent adverse life events on salivary cortisol in adolescents and young adults, while Engert et al. (2010) describe increased salivary cortisol output in young adults with low early life parental care. Carpenter et al. (2010) extend previous findings that early childhood physical abuse attenuates the salivary cortisol response to a psychosocial stress task in healthy adults.

The neuroanatomical (Oomen et al. 2010; Pryce et al. 2010), electrophysiological (Ali et al. 2010) and neurochemical alterations following ELS that lead to these behavioral changes are increasingly well understood. O'Malley et al. (2010) link alterations in central corticotrophin-releasing factor receptors to altered stress sensitivity. Matsuzaki et al. (2010) and Groenink et al. (2010) investigate the role of 5-HT1A receptors in fear conditioning, and startle reactivity and prepulse inhibition, respectively. Rodrigues et al. (2010) review the effects of ELS on the function of the dopaminergic system. Moreover, it becomes increasingly obvious that perinatal exposure to pharmacological stressors, such as alcohol (Marche et al. 2010) or cannabinoids (Campolongo et al. 2010), can be conceptualized as ELS, accompanied by altered stress sensitivity, motor, cognitive, and emotional function later on in life.

The increasing availability of easy and inexpensive genotyping techniques has facilitated the dramatic increase in research on genetic interactions with ELS in humans. Nugent et al. (2011) review this work with respect to the risk for developing depressive and anxiety disorders in adolescence and adulthood. Reif et al. (2010) demonstrate how adaptive and maladaptive impulsivity reflect interactions of neuronal nitric oxide synthase (NOS1) genotype with adverse family environment and stressful life events in adolescents. In their epidemiological study, Elzinga et al. (2010) report that brain-derived neurotrophic factor (BDNF) genotype interacts with ELS and recent life stress to lower serum BDNF levels in adults with a history of depression.

We realize that much of the work contained in this Special Issue departs from what readers usually expect to see in Psychopharmacology. Several of our invited authors, and a number of reviewers, made just that observation. However, we believe that the use of preclinical ELS models as translational models to evaluate the efficacy of novel therapeutic interventions represents an exciting new avenue of investigation. Two papers highlight this approach: Jones et al. (2010) describe the effects of the mGlu2/3 receptor agonist LY379268 on recognition memory deficits induced by ELS in rats, while Marche et al. (2010) report on the effects of the PPARalpha agonist fenofibrate in a rat model of perinatal alcohol exposure. And ELS has already shown preliminary promise in predicting clinical treatment response (Nemeroff et al. 2003). We hope a better understanding of the role of ELS in pathogenesis will help psychopharmacologists to better identify and characterize drug-responsive phenotypes, and in turn facilitate the identification of novel targets for drug development.

\section{References}

Ali I, Salzberg MA, Grench C, Jones NC (2010) Electrophaysiological insights into the enduring effects of early life stress on the brain. Psychopharmacology (Berl).

Campolongo P, Trezza V, Ratano P, Palmery M, Cuomo V (2010) Developmental consequences of perinatal cannabis exposure: behavioral and neuroendocrinological effects in adult rodents. Psychopharmacology (Berl).

Carpenter LL, Shattuck TT, Tyrka AR, Geracioti TD, Price LH (2010) Effect of childhood physical abuse on cortisol stress response. Psychopharmacology (Berl).

Caspi A, Sugden K, Moffitt TE, Taylor A, Craig IW, Harrington H, McClay J, Mill J, Martin J, Braithwaite A, Poulton R (2003) Influence of life stress on depression: moderation by a polymorphism in the 5-HTT gene. Science 301:386-389

Claessens SEF, Daskalakis NP, Van den Veen R, Oitzl MS, De Kloet ER, Champagne DL (2010) Development of individual differences in stress responsiveness: an overview of factors mediating the outcome of early life experiences. Psychopharmacology (Berl).

Elzinga BM, Molendijk ML, Oude Voshaar RC, Bus BA, Prickaerts J, Spinhoven P, Penninx BJ (2010) The impact of childhood abuse and recent stress on serum brain-derived neurotrophic factor and the moderating role of BDNF Val(66)Met. Psychopharmacology (Berl).

Engert V, Efanov SI, Dedovic K, Dagher A, Pruessner JC (2010) Increased cortisol awakening response and afternoon/evening cortisol output in healthy young adults with low early life parental care. Psychopharmacology (Berl).

Enoch MA (2010) The role of early life stress as a predictor for alcohol and drug dependence. Psychopharmacology (Berl).

Gluckman PD, Hanson MA (2004) Living with the past: evolution, development, and patterns of disease. Science 305:1733-1736

Groenink L, Bijlsma EY, Van Bogaert MJV, Oosting RS, Olivier B (2010) Serotonin 1A receptor deletion does not interact with maternal separation-induced increases in startle reactivity and prepulse inhibition deficits. Psychopharmacology (Berl).

Hagan MJ, Roubinov DS, Gress-Smith J, Luecken LJ, Sandler IN, Wolchik S (2010) Positive parenting during childhood moderates the impact of recent negative events on cortisol activity in parentally bereaved youth. Psychopharmacology (Berl).

Hedges DW, Woon FL (2010) Early-life stress and cognitive outcome. Psychopharmacology (Berl).

Heim C, Owens MJ, Plotsky PM, Nemeroff CB (1997) The role of early adverse life events in the etiology of depression and 
posttraumatic stress disorder. Focus on corticotropin-releasing factor. Ann N Y Acad Sci 821:194-207

Jones CA, Brown AM, Auer DP, Fone KCF (2010) The mGluR2/3 agonist LY379268 reverses post-weaning social isolation-induced recognition memory deficits in rats. Psychopharmacology (Berl).

Krug EG, Dahlberg TT, Mercy JA, Zwi AB, Lozano R (eds) (2002) World report on violence and health. World Health Organization, Geneva

Marche K, Danel T, Bordet R (2010) Fetal alcohol-induced hyperactivity is reversed by treatmant with the PPRal[ha agonist fenofibrate in a rat model. Psychopharmacology (Berl).

Markham JA, Koenig JI (2010) Prenatal stress: role in psychotic and depressive diseases. Psychopharmacology (Berl).

Matsuzaki H, Izumi T, Horinouchi T, Boku S, Inoue T, Yamaguchi T, Yoshido T, Matsumoto M, Togashi H, Miwa S, Koyama T, Yoshioka S (2010) Juvenile stress attenuates the dorsal hippocampal postsynaptic 5-HT1A receptor function in adult rats. Psychopharmacology (Berl).

McGowan PO, Szyf M (2010) The epigenetics of social adversity in early life: implications for mental health outcomes. Neurobiol Dis 39:66-72

Nemeroff CB, Heim CM, Thase ME, Klein DN, Rush AJ, Schatzberg AF, Ninan PT, McCullough JP Jr, Weiss PM, Dunner DL, Rothbaum BO, Kornstein S, Keitner G, Keller MB (2003) Differential responses to psychotherapy versus pharmacotherapy in patients with chronic forms of major depression and childhood trauma. Proc Natl Acad Sci USA 100:14293-14296

Nugent NR, Tyrka AR, Carpenter LL, Price LH (2011) Geneenvironment interactions: early life stress and risk for depressive and anxiety disorders. Psychopharmacology (Berl).

O'Mahony SM, Hyland NP, Dinan TG, Cryan JF (2010) Maternal separation as a model of brain-gut axis function. Psychopharmacology (Berl).

O'Malley D, Dinan TG, Cryan JF (2010) Neonatal maternal separation in the rat impacts on the stress responsivity of central corticotropin-releasing factr receptors in adulthood. Psychopharmacology (Berl).

Oomen CA, Soeters H, Audureau N, Vermunt L, Van Hasselt FN, Manders EMM, Joels M, Krugers H, Lucassen PJ (2010) Early maternal deprivaton affects dentate gyrus structure and emotional learning in adult female rats. Psychopharmacology (Berl).

Ouellet-Morin I, Dionne G, Lupien SJ, Muckle G, Cote S, Perusse D, Tremblay RE, Boivin M (2010) Prenatal alcohol exposure and cortisol activity in 19-month-old toddlers: an investigation of the moderating effects of sex and testosterone. Psychopharmacology (Berl).

Pechtel P, Pizzagalli DA (2010) Effects of early life stress on cognitive and affective function: an integrated review of human literature. Psychopharmacology (Berl).

Peleg-Raibstein D, Feldon J (2010) Differential effects of postweaning juvenile stress on the behaviour of C57BL/6 mice in adolescence and adulthood. Psychopharmacology (Berl).

Pryce CA, Aubert Y, Maier C, Pearce PC, Fuchs E (2010) The developmental impact of prenatal stress, prenatal dexamethasone and postnatal social stress on physiology, behaviour and neuroanatomy of primate offspring: studies in rhesus macaque and common marmoset. Psychopharmacology (Berl).

Reif A, Kiive E, Kurrikoff T, Paaver M, Herterich S, Konstabel K, Tulviste T, Lesch KP, Harro J (2010) A functional NOS1 promoter polymorphism interacts with adverse environment on functional and dysfunctional impulsivity. Psychopharmacology (Berl).

Rodrigues AJ, Leao P, Carvalho M, Almeida OFX, Sousa N (2010) Potential programming of dopaminergic circits by early life stress. Psychopharmacology (Berl).

Rudolph KD, Troop-Gordon W, Granger DA (2010) Individual differences in biological stress responses moderate the contribution of early peer victimization to subsequent depressive symptoms. Psychopharmacology (Berl).

Scott KM, Smith DR, Ellis PM (2010) Prospectively ascertained child maltreatment and its association with DSM-IV mental disorders in young adults. Arch Gen Psychiatry 67:712-719

Schmidt MV, Wang XD, Meijer OC (2010) Early life stress paradigms in rodents: potential animal models of depression? Psychopharmacology (Berl).

Turner-Cobb JM, Rixon L, Jessop DS (2010) Hypothalamic-pituitaryadrenal axis activity and upper respiratory tract infection in young children transitioning to primary school. Psychopharmacology (Berl).

Van Waes V, Enache M, Berton O, Vinner E, Lhermitte M, Maccari S, Darnaudery M (2010) Effect of prenatal stress on alcohol preference and sensitivity to chronic alcohol exposure in male rats. Psychopharmacology (Berl).

Yehuda R, Flory JD, Pratchett LC, Buxbaum J, Ising M, Holsboer F (2010) Putative biological mechanisms for the association between early life adversity and the subsequent development of PTSD. Psychopharmacology (Berl) 212:405-417 